\title{
Chronic Treatment with Extended Release Methylphenidate Does Not Alter Dopamine Systems or Increase Vulnerability for Cocaine Self-Administration: A Study in Nonhuman Primates
}

\author{
Kathryn E Gill', Peter J Pierre ${ }^{1,4}$, James Daunais', Allyson J Bennett ${ }^{1,5}$, Susan Martelle', H Donald Gage ${ }^{2}$, \\ James M Swanson ${ }^{3}$, Michael A Nader ${ }^{1,2}$ and Linda J Porrino*, 1,2 \\ 'Department of Physiology and Pharmacology, Wake Forest School of Medicine, Winston Salem, NC, USA; ${ }^{2}$ Department of Radiological Sciences, \\ Wake Forest School of Medicine, Winston Salem, NC, USA; ${ }^{3}$ Child Development Center, Department of Pediatrics, University of California, Irvine, \\ Irvine, CA, USA
}

\begin{abstract}
Despite the widespread use of stimulant medications for the treatment of attention deficit hyperactivity disorder, few studies have addressed their long-term effects on the developing brain or susceptibility to drug use in adolescence. Here, we determined the effects of chronic methylphenidate (MPH) treatment on brain dopamine (DA) systems, developmental milestones, and later vulnerability to substance abuse in juvenile nonhuman primates. Male rhesus monkeys (approximately 30 months old) were treated daily with either a sustained release formulation of $\mathrm{MPH}$ or placebo ( $N=8$ per group). Doses were titrated to achieve initial drug blood serum levels within the therapeutic range in children and adjusted throughout the study to maintain target levels. Growth, including measures of crown-rump length and weight, was assessed before and after I year of treatment and after 3-5 months washout. In addition, positron emission tomography scans were performed to quantify binding availability of D2/D3 receptors and dopamine transporters (DATs). Distribution volume ratios were calculated to quantify binding of $\left[{ }^{18} \mathrm{~F}\right]$ fluoroclebopride (DA D2/D3) and $\left[{ }^{18} \mathrm{~F}\right]-(+)-\mathrm{N}$-(4-fluorobenzyl)-2 $\beta$-propanoyl$3 \beta$-(4-chlorophenyl)tropane (DAT). Chronic MPH did not differentially alter the course of weight gain or other measures of growth, nor did it influence DAT or D2/D3 receptor availability after I year of treatment. However, after washout, the D2/D3 receptor availability of $\mathrm{MPH}$-treated animals did not continue to decline at the same rate as control animals. Acquisition of intravenous cocaine selfadministration was examined by first substituting saline for food reinforcement and then cocaine doses $(0.00 \mathrm{I}-0.1 \mathrm{mg} / \mathrm{kg}$ per injection) in ascending order. Each dose was available for at least five consecutive sessions. The lowest dose of cocaine that maintained response rates significantly higher than saline-contingent rates was operationally defined as acquisition of cocaine reinforcement. There were no differences in rates of acquisition, overall response rates, or cocaine intake as a function of cocaine dose between groups. In an animal model that closely mimics human development; chronic treatment with therapeutic doses of sustained release MPH did not have a significant influence on the regulation of DATs or D2/D3 receptors, or on standard measures of growth. Furthermore, this treatment regimen and subsequent drug washout did not have an impact on vulnerability to cocaine abuse.
\end{abstract}

Neuropsychopharmacology (2012) 37, 2555-2565; doi:10.1038/npp.2012.1 I7; published online 18 July 2012

Keywords: dopamine; addiction and substance abuse; monkeys; methlyphenidate; attention deficit hyperactivity disorder; PET

\section{INTRODUCTION}

Attention deficit hyperactivity disorder (ADHD) is the most commonly diagnosed psychiatric disorder of childhood and adolescence, affecting an estimated $7.8 \%$ of children ages $4-17$

\footnotetext{
*Correspondence: Dr LJ Porrino, Department of Physiology and Pharmacology, Wake Forest School of Medicine, One Medical Center Drive, Winston Salem, NC 27I57-1083, USA, Tel: + I 3367168590 , Fax: + I 336 7|6 850 I, E-mail: Iporrino@wakehealth.edu

${ }^{4}$ Current address: Wisconsin National Primate Research Center, Madison, WE 537I5, USA

${ }^{5}$ Current address: Harlow Center for Biological Psychology, Madison, WI 537I5, USA

Received 5 March 20 2; revised 23 May 2012; accepted 30 May 2012
}

in the United States (Visser et al, 2007). Stimulant medications including methylphenidate (MPH) and amphetamine have been the most frequently prescribed treatments for ADHD since their introduction in the 1960s, and their use has steadily increased over time (Swanson and Volkow, 2009).

$\mathrm{MPH}$ acts at the dopamine transporter (DAT) to increase concentrations of extracellular dopamine (DA) in the mesocorticolimbic and mesostriatal systems by blocking reuptake (Schweri et al, 1985; Volkow et al, 1998). Like cocaine and methamphetamine, there is evidence that MPH causes significant neuroadaptations within the DA system (Self, 2004; Wolf et al, 2004). However, few studies have examined long-term consequences following chronic use of MPH in children and adolescents. Thus, one goal of this 
study was to characterize the changes in DAT and DA receptor function following 1 year of $\mathrm{MPH}$ treatment in juvenile nonhuman primates.

Although there is considerable evidence of the efficacy of stimulant medications in reducing the symptoms of $\mathrm{ADHD}$, there are questions about the potential for adverse consequences accompanying chronic treatment. There is evidence for modest growth suppression (Safer et al, 1972; Zhang et al, 2010), although this is far from consistent. Some studies of MPH-treated children have reported reduced growth curves for both height and weight compared with age-matched controls (Swanson et al, 2007), whereas others reported no effects on growth (Biederman et al, 2010). Thus, a second goal of this study was to characterize growth measures in juvenile monkeys treated with MPH and control animals.

One of the greatest concerns surrounding the use of stimulant medications in childhood is an increased risk of substance abuse in adolescence. Several studies of ADHD children have suggested that treatment does not increase (Biederman et al, 2008; Mannuzza et al, 2008; Molina et al, 2009), or may even have a protective effect against the development of substance abuse disorder (Barkley et al, 2003; Biederman et al, 1999). However, at least one study found some evidence for an increased risk of tobacco and cocaine use in adults treated as children (Lambert and Hartsough, 1998).

As a result of the complex interactions among dosing regimens, diagnoses, duration of treatment, comorbidity, and so on in studies of children and adolescents with $\mathrm{ADHD}$, there have been attempts to answer this question using animal models, almost exclusively in rodents. Although some studies have reported that MPH-treated animals are more susceptible to the rewarding effects of cocaine (Brandon et al, 2001), other studies have documented reduced rates of cocaine self-administration (Thanos et al, 2007), or less sensitivity to cocaine (Andersen et al, 2002; Carlezon et al, 2003) post-MPH treatment. The equivocal results may be due to differences in routes of administration, drug doses, drug formulations, and durations of treatment (Volkow and Insel, 2003). The discrepancies underscore a major problem with developmental studies in rodents, which is the relatively short window of pre- and peri-adolescence/adolescence in this species.

Given the limitations of studies in rodents, this study employed juvenile nonhuman primates to measure the effects of chronic MPH administration. Nonhuman primates provide exceptional models for developmental research because they undergo relatively long childhood and adolescent periods, marked by hormonal and physiological maturation similar to humans (Bennett and Pierre, 2010). In addition, nonhuman primates have close homology to humans in terms of neuroanatomy and neurochemistry of the DA system, as well as complex social and cognitive behavioral repertoires (Weerts et al, 2007).

Recently, controlled-release formulations of MPH such as Concerta and Metadate $\mathrm{CD}$ have replaced immediate release, short-acting formulations such as Ritalin as the most commonly prescribed form of medication. In children, these formulations of $\mathrm{MPH}$ have been reported to be clinically effective for as long as $12 \mathrm{~h}$ after administration and obviate the need for repeated dosing throughout the day (Pelham et al, 2001; Swanson et al, 2004). They make use of first-order drug delivery profiles to overcome the acute tolerance that occurs with immediate-release dosing and are designed to release an initial bolus followed by continuous dosing for approximately $6 \mathrm{~h}$ after administration (Swanson et al, 1999). In order to best model current clinical practice, nonhuman primates in this study were treated with a controlled-release formulation of $\mathrm{MPH}$ at doses targeted to be within a clinically relevant range (Swanson and Volkow, 2003).

Thus, the goals of this study were to evaluate the effects of chronic administration of a commonly used formulation of MPH on measures of DA function, growth, and vulnerability to the reinforcing effects of cocaine in juvenile nonhuman primates.

\section{SUBJECTS AND METHODS}

\section{Subjects}

Sixteen socially housed young male rhesus monkeys were studied in two cohorts (cohort $=8$; mean age 40.5 and 38.0 months at time of initiation of drug treatment). Each cohort was divided into two groups ( $N=4$, housed as a unit): drug treated and vehicle treated. Groups were initially matched as closely as possible on baseline age and body weight. Monkeys were fed individually and maintained on a $200 \mathrm{kcal}$ diet (Purina 5038) as prescribed for young animals at our primate center with ad libitum water. Diet amounts were calculated for each individual, remaining chow was weighed after each meal and chow amounts were adjusted as body weight increased. All animals were considered in the late juvenile/early adolescent stage of development at the start of the study based on a constellation of measurements including weight, crown-rump length, testis size, canine length, femur length, and abdominal and chest circumference (Bennett and Pierre, 2010). Animals were trained to present their leg for conscious femoral venipuncture. Animal housing, handling, and experimental procedures were performed in accordance with the 2003 National Research Council Guidelines for the Care and Use of Mammals in Neuroscience and Behavioral Research. Experimental protocols and environmental enrichment plans were approved by the Animal Care and Use Committee of Wake Forest University.

\section{Phase 1: Drug Treatment, Developmental, and DA System Markers}

Drugs and dosing procedures. The contents of individual Metadate CD (generously provided by UCB, Smyrna, GA) capsules $(20 \mathrm{mg}$ ) were suspended in $10 \mathrm{ml}$ of pudding (Hunts Snack Pack, Con Agra Foods, NE). Control subjects received $10 \mathrm{ml}$ of pudding only. Doses were chosen to approximate clinically relevant levels in children of $10-15 \mathrm{ng} / \mathrm{ml}$ blood serum (Swanson and Volkow, 2003). All animals received one capsule $(20 \mathrm{mg})$ initially, then each monkey's dose was adjusted to target serum levels. Serum levels were re-determined monthly and doses adjusted to account for weight gain and any changes in MPH levels. Blood was collected $1.5 \mathrm{~h}$ following dose consumption to target peak drug levels, centrifuged, serum fraction separated and frozen 
at $-70{ }^{\circ} \mathrm{C}$. Analysis was performed (Medtox Laboratories, MN) using gas chromatography. Preliminary studies showed that blood serum levels after the immediate-release phase were maintained during the $2-6 \mathrm{~h}$ extended release phase post-administration. For $1 \mathrm{~h}$ each morning monkeys were separated into individual quadrants of the home cage for feeding and dosing and then returned to their social groups. Monkeys voluntarily consumed drug or vehicle through a $60 \mathrm{ml}$ syringe. After $1 \mathrm{~h}$, each animal's chow was removed and weighed and then adjusted to accommodate a positive growth trajectory (NRC/NAS, 2003). The amount of chow consumed did not differ between groups over the course of the study. This procedure was repeated daily for 12 months.

Morphometric measurements. Morphometric measurements were taken at baseline (2 weeks before initiation of drug administration), treatment (after 12 months of drug administration), and washout (3-5 months after cessation of treatment). Measurements were collected following anesthesia with ketamine hydrochloride (15 mg/kg, IM). Crown-rump length $(\mathrm{cm})$ was measured using a $60 \mathrm{~cm}$ sliding caliper (Anthropometer Model 01290; Lafayette Instrument, Lafayette, IN) by measuring from the most distal part of the left ischial callosite to the top of the skull. Body mass index (BMI) was calculated as body weight/ crown-to-rump length.

Positron emission tomography (PET) imaging of DA D2/ $D 3$ receptors and DATs. PET imaging studies to measure DA D2/D3 receptor and DAT availability were carried out at similar time points as the morphometric measures: baseline, treatment, and washout. Treatment measurements were made within 1 week following the cessation of treatment, and at least $24 \mathrm{~h}$ after final dosing to allow for drug clearance. Washout scans were performed 3-5 months later. At each time point, T1 weighted magnetic resonance imaging (MRI) scans were acquired on a 3.0T GE Scanner for co-registration and definition of regions of interest (ROIs).

Details of PET data acquisition procedures for both D2/ D3 receptors and DATs have been described previously (Czoty et al, 2007). Briefly, monkeys were anesthetized with $10 \mathrm{mg} / \mathrm{kg}$ ketamine, intubated, and anesthesia maintained by $1.5 \%$ isoflurane. Once in the scanner, a venous catheter was inserted percutaneously for tracer injection. To quantify D2/D3 receptor availability, approximately $5 \mathrm{mCi}$ of $\left[{ }^{18} \mathrm{~F}\right]$ fluoroclebopride (FCP), a high-affinity D2/D3 ligand, was injected followed by $3 \mathrm{ml}$ heparinized saline. On a second scanning day (separated by at least 1 week), approximately $5 \mathrm{mCi}$ of $\left[{ }^{18} \mathrm{~F}\right]-(+)-\mathrm{N}$-(4-fluorobenzyl)- $2 \beta$ propanoyl-3 $\beta$-(4-chlorophenyl)tropane (FCT) was injected to quantify DAT.

To eliminate movement during the scan, a paralytic $(0.07 \mathrm{mg} / \mathrm{kg}$ vercuronium $\mathrm{Br}$, i.v.) was administered $15 \mathrm{~min}$ before the start of image acquisition. Respiration was maintained by a ventilator with supplemental doses administered as needed. Body temperature was maintained by a heating pad, fluids maintained by intravenous normal saline, and vital signs monitored throughout. At scan conclusion, animals received an injection of neostigmine $(0.07 \mathrm{mg} / \mathrm{kg})$ and glycopyrrolate $(0.02 \mathrm{mg} / \mathrm{kg})$ to reverse the paralytic effects. Once recovered, monkeys were returned to their home environments and monitored until normally behaving.

Image acquisition occurred on a GE Advance NXi PET Scanner (General Electric Systems, Milwaukee, WI) with an effective resolution of approximately $4 \mathrm{~mm}$. Data were analyzed using PMOD software (PMOD, Zurich, Switzerland). ROIs were drawn on coronal sections in the ventral striatum, caudate nucleus, and putamen of each monkey's MRI at each time point. PET scans were manually coregistered to the corresponding MRIs and ROIs transferred to co-registered PET images. The dependent measure was the distribution volume ratio (DVR), defined as the distribution volume of the radiotracer in the ROI relative to the distribution volume of the radiotracer in a receptorless reference region (cerebellum). DVRs were determined by using the 'Logan method' of analysis as implemented in PMOD (Logan et al, 1996). DVRs were calculated for bilateral caudate nucleus, putamen, and ventral striatum for each PET scan.

Statistical analysis. Morphometric data (body weight, crown-rump length, and BMI) and PET data (D2-like receptor and DAT DVRs) were analyzed by means of a two-way analysis of variance (ANOVA) (treatment grouptime point; time as a repeated measure), followed by posthoc comparisons (Tukey tests) where appropriate. In all cases, $p<0.05$ was considered statistically significant.

\section{Phase 2: Cocaine Self-Administration}

After completion of phase 1 testing, monkeys were individually housed with visual and auditory contact with each other, fitted with aluminum collars (Primate Products, Redwood City, CA) and trained to sit calmly in a primate chair (Primate Products). Monkeys were weighed weekly and fed enough food daily (Purina Monkey Chow and fresh fruit and vegetables) to accommodate normative growth (NRC/NAS, 2003) while maintaining food-based responding. Water was available ad libitum.

Surgery. Under sterile conditions, each monkey was prepared with a chronic indwelling venous catheter, implanted in the femoral or jugular vein. The distal end of the catheter was attached to a subcutaneous vascular port (Access Technologies, Skokie, IL), as described previously (Czoty et al, 2005). Each port and catheter was filled with heparinized saline solution (100 units/ml) after every experimental session to prolong catheter patency. Before each self-administration session, the animal's back was cleaned with chlorhexidine acetate solution and 95\% EtOH and the port was connected to the infusion pump via a 22-gauge Huber Point Needle (Access Technologies). Before starting the session, the pump was operated for approximately $3 \mathrm{~s}$ to fill the port and catheter line with the dose of cocaine available for that session.

Apparatus. The apparatus was a ventilated, sound-attenuating chamber $(1.5 \times 0.74 \times 0.76 \mathrm{~m}$; Med Associates, East Fairfield, VT) consisting of two photo-optic switches (Model 117-1007; Stewart Ergonomics, Furlong, PA) on one side with a horizontal row of three stimulus lights 
positioned above each switch. A food receptacle between the switches was connected to a pellet dispenser (Med Associates) for delivery of 1-g banana-flavored food pellets (Bio-Serv, Frenchtown, NJ). An infusion pump (Cole-Palmer, Chicago, IL), which delivered solutions at a rate of approximately $1.5 \mathrm{ml} / 10 \mathrm{~s}$, was located on the top of the chamber.

Procedure. Monkeys were trained to respond on the left or right response switch, under a fixed-ratio (FR) 30 schedule of reinforcement in which a food pellet was delivered after the 30th response, followed by a $10 \mathrm{~s}$ timeout. Sessions ended after 15 or 30 reinforcers (depending on the monkey) or $60 \mathrm{~min}$, whichever occurred first. After catheter implantation, food-maintained responding was re-established and, when stable ( $<20 \%$ variability over three consecutive sessions with no trends in responding), saline was substituted for food pellets for at least five consecutive sessions and until responding declined by at least $80 \%$ of food-reinforced responding for three consecutive sessions with no trends in responding. The total number of sessions needed to meet this criterion is presented (Table 2). Next, food-maintained responding was re-established and then different doses of cocaine $\mathrm{HCl}$ (National Institute on Drug Abuse, Bethesda, MD, dissolved in sterile $0.9 \%$ saline) were substituted for the food pellets in ascending order from $0.001 \mathrm{mg} / \mathrm{kg}$ per injection, increasing in half log units to $0.1 \mathrm{mg} / \mathrm{kg}$ per injection. For cocaine substitution studies, sessions ended after 30 injections or $60 \mathrm{~min}$, whichever occurred first. Each dose was available for at least five consecutive sessions until responding was deemed stable (response rate mean $\pm 20 \%$ with no trends for three consecutive sessions). There was a return to food-reinforced responding for at least three sessions before the next cocaine dose was tested, until the cocaine dose-response curve had been generated.

Statistical analysis. To assess acquisition of cocaine reinforcement, a cocaine dose was operationally defined as reinforcing by using two-tailed $t$-tests comparing 3-day mean response rates for a given dose of cocaine to mean response rates when saline was available. Survival curves were generated and the number of monkeys that acquired at each cocaine dose was compared for both groups of monkeys. Mean response rates (responses per second) and total cocaine intake ( $\mathrm{mg} / \mathrm{kg}$ per session) were calculated and dose-response curves were compared between groups using repeatedmeasures ANOVA, followed by post-hoc analysis (Tukey test). In all cases, $p<0.05$ was considered statistically significant.

\section{RESULTS}

\section{Serum Concentrations}

Initial MPH doses were $20-40 \mathrm{mg}$ (average $=5.9 \pm 1.2 \mathrm{mg} / \mathrm{kg}$ (mean \pm SD) ) with serum levels averaging $10.73 \pm 1.10 \mathrm{ng} / \mathrm{ml}$ (mean $\pm \mathrm{SD})$. Over the course of the 12-month treatment period, dose increases resulted in final doses of $60 \mathrm{mg}$ in six animals and 20 and $120 \mathrm{mg}$ in the other two (average $=6.8 \pm 1.7 \mathrm{mg} / \mathrm{kg} \quad($ mean $\pm \mathrm{SD})$ ) and final serum levels of $13.623 \pm 1.15 \mathrm{ng} / \mathrm{ml}$ (mean $\pm \mathrm{SD}$ ). There was no relationship between serum levels or doses and changes in growth or DA markers.

\section{Morphometrics}

Two-way repeated-measures (time $\times$ drug condition) ANOVAs were used to analyze growth data. There were significant main effects of time in all three morphometric measures (weight: $\mathrm{F}_{2,28}=113.04, p<0.001$; crown-to-rump: $\left.\mathrm{F}_{2,28}=116.68, \quad p<0.001 ; \quad \mathrm{BMI}: \mathrm{F}_{2,28}=40.49, \quad p<0.001\right)$, indicating that the monkeys were growing over the study period (Figure 1). There were no significant effects of drug treatment on any measure (weight: $\mathrm{F}_{1,14}=0.027$; crown-torump: $\left.\mathrm{F}_{1,14}=0.035 ; \mathrm{BMI}: \mathrm{F}_{1,14}=0.09\right)$, indicating that control and MPH-treated animals were growing at similar rates. Finally, the interaction of treatment with time was not significant for any measure.

\section{PET Measurements: D2-Like Receptor Availability}

Two-way repeated-measures ANOVAs confirmed significant main effects of time in the caudate nucleus, putamen, and ventral striatum (Caud: $\mathrm{F}_{2,28}=14.70$, $p<0.001 ;$ Put: $\mathrm{F}_{2,28}=27.59, p<0.001 ; \mathrm{VS}: \mathrm{F}_{2,28}=12.69$; $p<0.001)$, indicating that $\mathrm{D} 2 / \mathrm{D} 3$ receptor availability decreased from baseline through treatment and washout (Figures 2 and 3). There were no significant main effects of drug treatment in any of the brain regions (Caud: $\mathrm{F}_{1,14}=0.032$; Put: $\mathrm{F}_{1,14}=0.024 ; \mathrm{VS}: \mathrm{F}_{1,14}=0.042$ ). This is illustrated in Figure 3, which depicts a representative animal from both the control- and MPH-treated groups at baseline and treatment time points. Both animals had reduced D2/ D3 receptor availability after treatment, but did not differ from each other.

There was a significant interaction between drug and time in the putamen $\left(\mathrm{F}_{2,28}=4.32, p<0.05\right.$; Figure 2$)$. Post-hoc $t$-tests on the absolute value of the DVRs between treatment and control groups were not significant. However, there was a significant difference between control- and MPH-treated animals in the magnitude of the change in DVR (calculated as washout DVR-treatment DVR) between the treatment and washout time points in the putamen $\left(t_{14}=3.11\right.$; $p<0.01)$. This suggests that, over the course of washout, D2/D3 receptor availability in the putamen of MPH-treated monkeys did not continue to decrease at the same rate as in control monkeys.

\section{DAT Availability}

As washout scans could not be completed for cohort 2 because of unavailability of the ligand, results are presented for cohort 1 for three time points (baseline, treatment, and washout) and for both cohorts for two time points (baseline and treatment). In cohort 1 , a two-way repeated-measures ANOVA (time $\times$ drug condition) was run on DVRs measured in the caudate nucleus, putamen, and ventral striatum. There were no significant main effects of time (Caud: $\mathrm{F}_{2,10}=0.118$; Put: $\mathrm{F}_{2,10}=0.645$; VS: $\mathrm{F}_{2,10}=1.643$ ) or drug condition (Caud: $\mathrm{F}_{1,5}=0.324$; Put: $\mathrm{F}_{1,5}=0.005$; VS: $\left.\mathrm{F}_{1,5}=0.494\right)$ in any brain region and no significant interactions (Table 1). A second ANOVA (time $\times$ drug condition) was performed to examine DAT availability in both cohorts, excluding the washout scans. There were again no significant effects of time (Caud: $\mathrm{F}_{1,13}=2.675$; Put: $\mathrm{F}_{1,13}=0.054$; VS: $\mathrm{F}_{1,13}=1.013$ ) or drug condition 

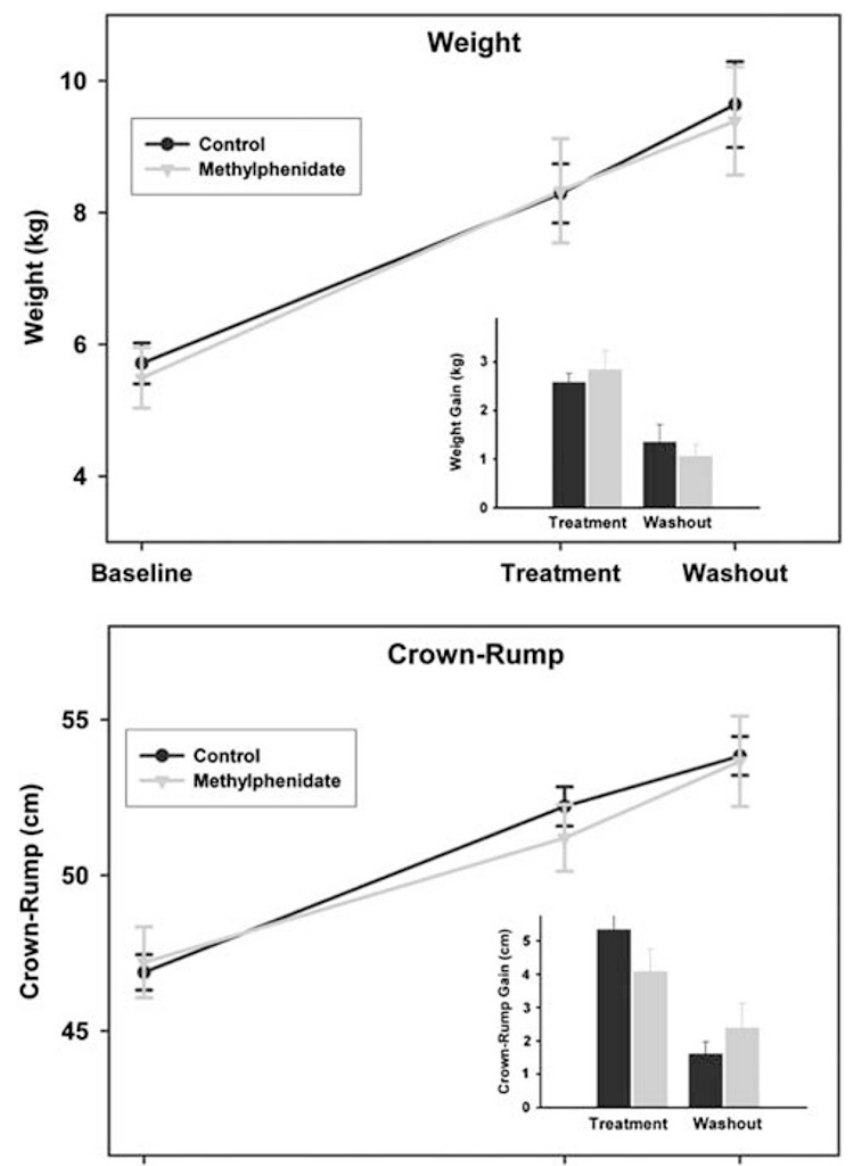

Baseline

Treatment Washout

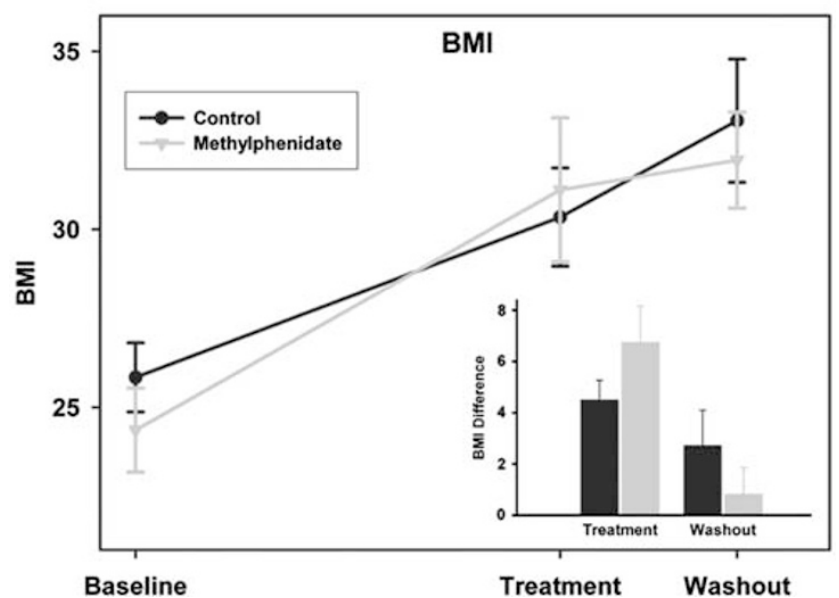

Figure I Standard measures of growth, weight, crown-to-rump length and body mass index (BMI), were measured at baseline, after 12 months of treatment, and after 3-5 months of drug washout. Animals in both control and MPH treatment groups showed normal gains in weight and length over the study period. No differences were observed between groups. Insets depict the absolute change in weight, crown-rump length, and BMI between baseline and treatment and treatment and washout time points.

(Caud: $\mathrm{F}_{1,13}=0.669$; Put: $\mathrm{F}_{1,13}=0.016$; VS: $\mathrm{F}_{1,13}=0.289$ ) in any brain region and no significant interactions. Thus, DAT availability did not change over the course of development during the study and was not affected by chronic MPH treatment.
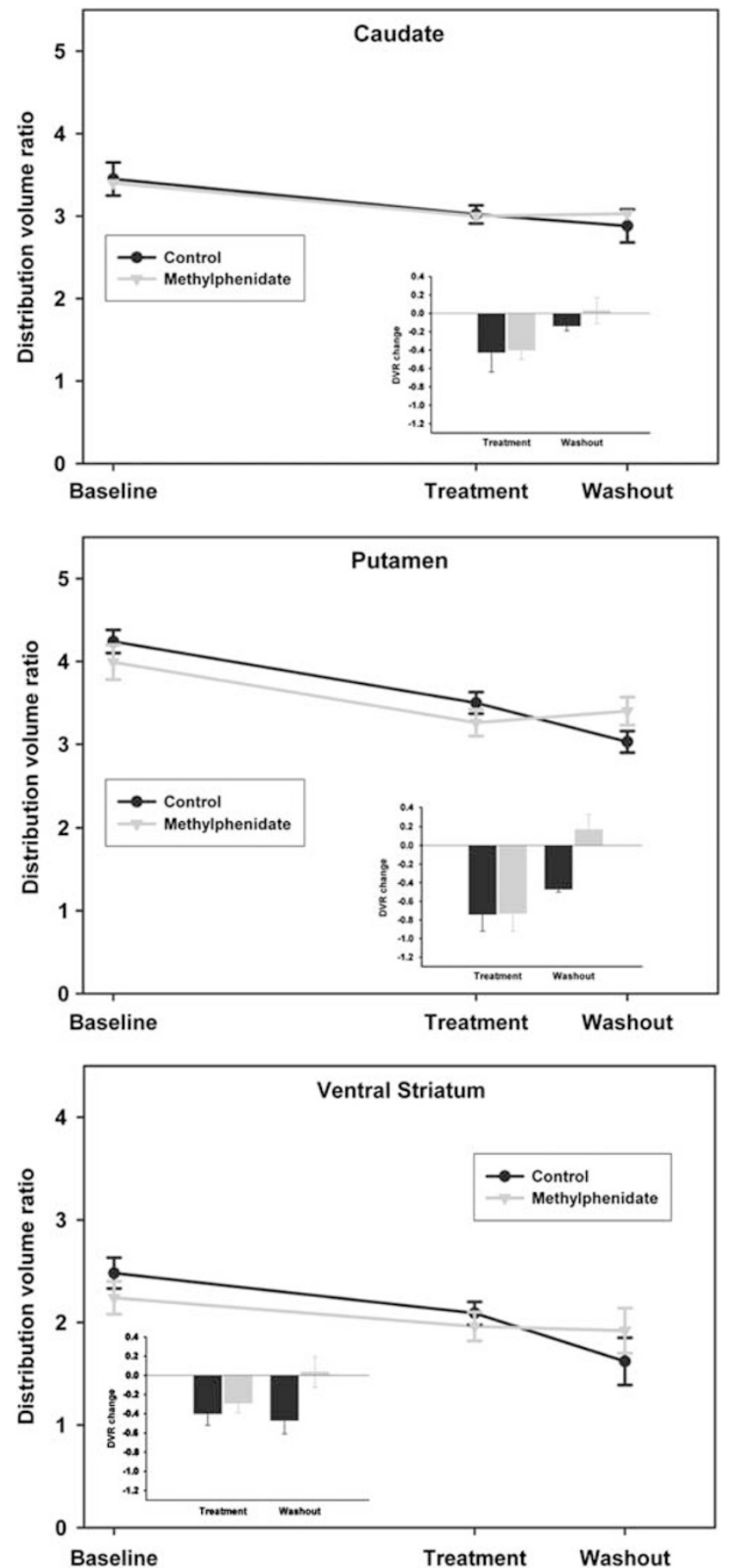

Figure 2 Dopamine D2/D3 receptor availability as measured by $\left.{ }^{18} \mathrm{~F}\right] \mathrm{FCP}$ in $\mathrm{MPH}$-treated and control monkeys in the caudate nucleus, putamen, and ventral striatal regions. Relative distribution volume ratios (mean \pm SEM) show no differences in D2/D3 receptor availability between control- and MPH-treated animals. However, a significant decrease in D2/ D3 receptor availability from baseline to the end of the treatment period was found in all three regions $(p<0.05)$. Insets depict the absolute change in distribution volume ratio (DVR) values between baseline and treatment and treatment and washout time points.

\section{Self-Administration}

There were no differences in baseline rates of food-reinforced responding between MPH- and control-treated monkeys (Table 2). After surgery and return to stable 
food-reinforced responding, saline was substituted for food presentation. There were no differences in the number of sessions required for responding to extinguish between $\mathrm{MPH}-$ and control-treated monkeys (Table 2). After a return
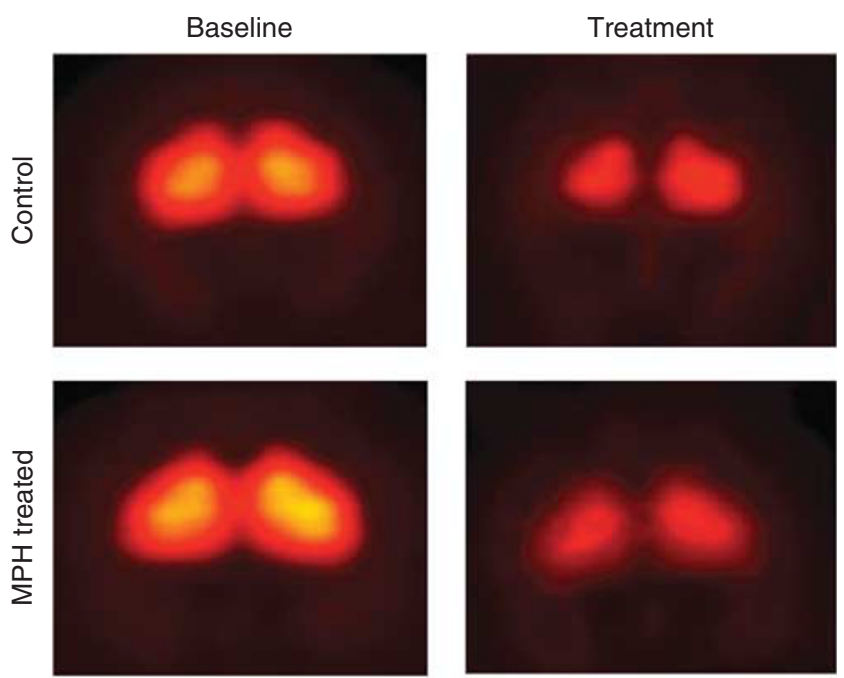

Figure 3 Binding of $\left[{ }^{18} \mathrm{~F}\right] \mathrm{FCP}$ to DA D2/D3 receptors in the striatum decreases over a 12-month period in control- and $\mathrm{MPH}$-treated animals. There were no differences in D2/D3 receptor availability between groups at either time point. to food-reinforced responding, acquisition of cocaine reinforcement was examined using ascending doses of cocaine, beginning with $0.001 \mathrm{mg} / \mathrm{kg}$. There were no differences in the number of monkeys that acquired cocaine reinforcement at each dose of cocaine between MPH- and control-treated monkeys (Figure 4a). Complete cocaine dose-response curves showed that, for both $\mathrm{MPH}$ - and control-treated monkeys, response rates $\left(\mathrm{F}_{5,70}=4.30\right.$; $p<0.01)$ and cocaine intake $\left(\mathrm{F}_{4,56}=58.11 ; p<0.0001\right)$ varied significantly as a function of cocaine dose (Figures $4 \mathrm{~b}$ and c). Response rates were characterized as an inverted $\mathrm{U}$-shaped function of dose (Figure $4 \mathrm{~b}$ ). There was not a significant main effect of treatment (MPH vs control). Cocaine intake increased monotonically as a function of dose in all monkeys and was not different in MPH- and control-treated monkeys (Figure 4c).

\section{DISCUSSION}

The results of this study show that prolonged treatment with therapeutic-level doses of an extended release formulation of MPH does not have a significant influence on physical growth or on the development of DA D2/D3 receptors or DAT in a nonhuman primate model. In addition, MPH treatment did not increase vulnerability to the reinforcing effects of cocaine when tested after the cessation of drug treatment in adolescence. These findings

Table I Effects of Methylphenidate Treatment on $\left[{ }^{18} \mathrm{~F}\right] \mathrm{FCT}$ Distribution Volume Ratios ${ }^{\mathrm{a}}$

\begin{tabular}{|c|c|c|c|c|c|c|}
\hline \multirow[t]{2}{*}{ Brain region } & \multicolumn{3}{|c|}{ Placebo treated $(N=8)$} & \multicolumn{3}{|c|}{ Methylphenidate treated $(\mathrm{N}=7)$} \\
\hline & Baseline & Treatment & Washout & Baseline & Treatment & Washout \\
\hline Putamen & $3.99 \pm 0.12$ & $3.94 \pm 0.23$ & $3.45 \pm 0.46$ & $4.01 \pm 0.26$ & $4.00 \pm 0.23$ & $3.78 \pm 0.51$ \\
\hline Ventral striatum & $2.29 \pm 0.15$ & $2.27 \pm 0.11$ & $2.11 \pm 0.25$ & $2.49 \pm 0.16$ & $2.31 \pm 0.14$ & $2.14 \pm 0.22$ \\
\hline
\end{tabular}

${ }^{a}$ Data represent distribution volume ratios expressed as means \pm SEM.

Dopamine transporter availability was measured before drug or vehicle treatment, after 12 months of treatment and 3-5 months after treatment cessation. One MPHtreated animal was removed from analysis because of a technical error during the baseline scan.

Table 2 Baseline Food-Maintained Responding and Number of Sessions for Response Extinction ${ }^{a}$

\begin{tabular}{lcclcc}
\hline Monkey & Food rates (responses/s) & No of extinction sessions & Monkey & Food rates (responses/s) & No of extinction sessions \\
\hline Saline-treated controls & & & Methylyphenidate-treated controls \\
R-1545 & $0.73(0.26)$ & 6 & R-1546 & $0.47(0.05)$ & 7 \\
R-1547 & $2.43(0.57)$ & 5 & R-1548 & $0.33(0.22)$ & 5 \\
R-1549 & $0.93(0.13)$ & 5 & R-1550 & $0.23(0.06)$ & 5 \\
R-1551 & $0.56(0.15)$ & 7 & R-1552 & $2.05(0.52)$ & 6 \\
R-1616 & $1.09(0.14)$ & 5 & R-1620 & $1.94(0.28)$ & 5 \\
R-1617 & $2.86(0.12)$ & 5 & R-1621 & $2.19(0.10)$ & 6 \\
R-1618 & $0.50(0.11)$ & 6 & R-1622 & $0.49(0.06)$ & 7 \\
R-1619 & $2.67(0.62)$ & 15 & R-1623 & $1.63(0.11)$ & 5 \\
Mean (SEM) & $1.41(0.38)$ & $6.75(1.29)$ & & $1.15(0.32)$ & $5.75(0.34)$ \\
\hline
\end{tabular}

${ }^{a}$ Data represent the mean \pm SD of the last three sessions of food-reinforced responding before saline substitution. 

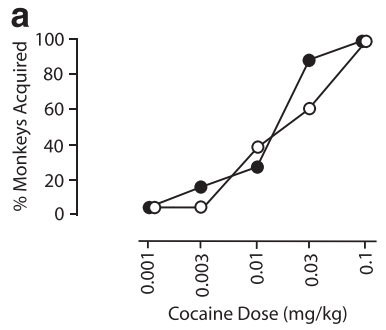

b

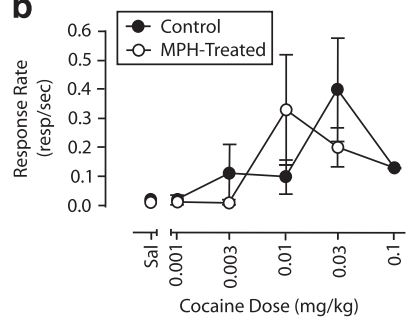

C

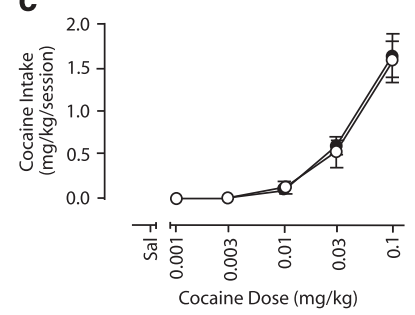

Figure 4 (a) Acquisition of cocaine reinforcement in MPH-treated and control monkeys. Percentage of MPH- (open symbols) and control-treated (closed symbols) monkeys that reached criteria to acquire cocaine self-administration at various doses of cocaine available under an FR 30 schedule of reinforcement. (b) Mean ( \pm SEM) rate of responding (responses per second) when saline or various doses of cocaine were available per session for MPHand control-treated monkeys. (c) Mean ( \pm SEM) cocaine intake (mg/kg per session). Each dose was available for at least five sessions and until responding was stable; data represent the mean of the last 3 days of availability for each animal.

directly address the impact of stimulant medication on three major areas of concern that have been identified in clinical studies of children treated for ADHD: physical growth, DA system development, and future vulnerability to substance abuse. The results of this investigation provide support for the hypothesis that the use of MPH for the treatment of childhood ADHD does not lead to long-term adverse developmental, neurobiological, or behavioral consequences over the course of treatment or later in adolescence.

There are several important features of this study. First, nonhuman primates provide exceptional models for developmental research because they undergo relatively long childhood and adolescent periods marked by hormonal and physiological maturation, as well as the development of complex social behavior and cognitive abilities that are similar to humans. Nonhuman primates in this study were between 37 and 54 months of age during MPH treatment, corresponding to approximately 9-13 years of age in children (Knickmeyer et al, 2010), well within the range at which treatment is often initiated in children. Another important feature was the use of an extended release formulation of MPH. The main advantage of these formulations is that they contain an immediate-release dose intended to act as an initial bolus and extended MPH release designed to maintain plasma concentrations for up to $6 \mathrm{~h}$ (Patrick et al, 2005), circumventing the need for multiple doses over the course of the day. The use of the extended release formulation, the most commonly prescribed form of $\mathrm{MPH}$, provides greater translational value to clinical practice.

\section{Growth}

In the present investigation of juvenile/adolescent nonhuman primates, there were no significant effects of extended release MPH treatment on measures of growth. Similarly, there were no differences between groups in total food consumption. In clinical literature, there has been considerable debate about the effects of stimulant therapy on growth rates. There have been reports of the suppression of the normal trajectory of height and weight gain with stimulant treatment (Safer et al, 1972; Zhang et al, 2010). A recent large multicenter study of the effects of extended release formulations of MPH reported significant suppression of growth rates for both height and weight over a 2-year treatment period, persisting over a 3-year follow-up (Swanson et al, 2007). However, other reports suggest that these effects on growth may attenuate over time and that final adult height is not impacted (Rapoport and InoffGermain, 2002). Another recent study with longer follow-up times reported no significant drug effects of growth (Biederman et al, 2010), consistent with an absence of effects in adulthood. In this study, the absence of any growth suppression may be due to the timing of treatment with respect to the periods of rapid growth. Environmental conditions that suppress growth may not have long-term consequences (Tanner, 1986) when growth rebound occurs after the precipitating condition is removed. It is possible that the washout period obscured any growth effects that would have emerged with continued treatment. Another possible reason for the absence of significant growth suppression was the treatment dose, as dose adjustment has been reported to rectify suppression in some children (Rapoport and Inoff-Germain, 2002). Higher doses may have resulted in more profound effects. Further investigation of the role of dose and duration of treatment is certainly warranted.

\section{DA D2/D3 Receptors and DATs}

As with growth, there was no overall effect of MPH on D2/ $\mathrm{D} 3$ receptor availability or DAT availability in striatal brain regions as measured by PET with $\left[{ }^{18} \mathrm{~F}\right] \mathrm{FCP}$ and $\left[{ }^{18} \mathrm{~F}\right] \mathrm{FCT}$, respectively. Although there were no differences in D2/D3 receptor availability between groups, there was a decrease in binding over time within the entire striatum. This decline in D2/D3 receptor availability during this developmental stage is well documented in humans (Meng et al, 1999; Seeman et al, 1987) and rats (Teicher et al, 1995) and is thought to be an effect of synaptic pruning. In a large post-mortem study, Seeman et al (1987) reported peak levels of D2/D3 receptor density at 5 years of age, followed by a sharp decline into early adolescence (14 years), and a gradual decrease throughout life. The ages of the monkeys in this study correspond well with the time period in human development of the steepest decline in striatal D2/D3 receptors.

Unlike the D2/D3 receptor family, there was no effect of development on the DAT, despite the fact that numerous studies have documented declines in DAT expression with age in primates and rodents (Hebert et al, 1999; Ma et al, 1999; Volkow et al, 1996). However, the decline in DAT seems to begin later in life than the decline in D2/D3 receptors (Volkow et al, 1996). In human post-mortem 
tissue, DAT expression in the basal ganglia peaked during adolescence (14-15 years), then slowly declined (Meng et al, 1999). The developmental window in this study was likely too early to detect the eventual decline in DAT density.

$\mathrm{MPH}$ did not alter the normal course of DA system development in our study sample. These results are in contrast to rodent studies that have shown effects of $\mathrm{MPH}$ on both D2/D3 receptors and DAT measures in the striatum. In rats, oral doses of $\mathrm{MPH}$ reportedly decrease D2/D3 receptor availability after 2 months, and increase availability after 8 months (Thanos et al, 2007), whereas other studies have reported sustained decreases in DAT density after chronic treatment (Izenwasser et al, 1999; Moll et al, 2001; Simchon et al, 2010). Interestingly, one study reported decreases in DAT density with twice-a-day injection of $\mathrm{MPH}$, but not with sustained release via osmotic mini-pump (Izenwasser et al, 1999), highlighting the importance of the drug's pharmacokinetics and the use of the controlled-release formulation. Thus, discrepancies between the results of the rodent models and the nonhuman primate model presented here could be due to differences in dosing regimens and pharmacokinetic profiles of the drug in the different species. Previous studies document intravenous $\mathrm{MPH}$ half-life in rats between $25 \mathrm{~min}$ ( $\mathrm{Gal}$ and Ames, 1977) and $105 \mathrm{~min}$ (Segal et al, 1976), whereas halflife in nonhuman primates has been reported to be $2.8 \mathrm{~h}$ (Wargin et al, 1983), although no recent studies directly compare the two species. The age of the animal at the time of treatment and the duration of treatment may also explain the inconsistent results. The peri-adolescent/adolescent period in a rodent is brief and difficult to target, yet studies in adult rodents miss the critical window of development during which this drug is most commonly administered.

Despite finding no overall effect of $\mathrm{MPH}$ on D2/D3 receptor availability, there was a significant interaction between drug and time. On further analyses, the MPHtreated animals had unchanged D2/D3 receptor availability after washout, whereas the control animals had continued to decrease. Although the absolute levels of radiotracer binding were not significantly different between groups at washout, the magnitude of the change between treatment and washout time points in the putamen did differ significantly between MPH- and control-treated animals. Similar trends were seen in the ventral striatum and caudate. These data indicate that, in the MPH-treated animals, there was a change in the trajectory of development to adult levels, which may suggest an interruption of the normal reduction of $\mathrm{D} 2 / \mathrm{D} 3$ receptor concentration over time. As D2/D3 receptor availability is regularly associated with vulnerability to drugs of abuse (Dalley et al, 2007; Nader et al, 2006; Volkow et al, 1999), differences in this system may be important for understanding vulnerability to substance abuse after treatment for ADHD. Further investigation is needed to determine if this effect persists after extended periods of abstinence from $\mathrm{MPH}$.

\section{Cocaine Reinforcement}

In contrast to the present results showing no differences in rates of acquisition to cocaine reinforcement, there have been several preclinical studies demonstrating that MPH treatment enhanced the reinforcing effects of cocaine
(Crawford et al, 2011; Harvey et al, 2011; Schenk and Izenwasser, 2002). There are several reasons for the discrepant results, but perhaps most relevant is the dose of cocaine initially made available to the animals. In these three studies, rats were initially exposed to relatively high cocaine doses $(0.25-0.75 \mathrm{mg} / \mathrm{kg})$, whereas this study began with doses well-below reinforcing doses. In this study, acquisition of reinforcement was operationally defined as response rates higher than when responding resulted in saline injections, whereas most other studies consider acquisition of a performance level (eg, the dose in which the animal receives 30 injections). Although we did not see differences in response rates across a wide range of cocaine doses, it is possible that if we had simply started with high doses, group differences would have emerged. Our current results support the observation that $\mathrm{MPH}$ treatment does not make adolescents more vulnerable to the reinforcing effects of cocaine.

These data in nonhuman primates support recent findings that have shown no increase in the rates of substance abuse among adults and adolescents treated as children with stimulant medications for ADHD. Although there is a strong association between a diagnosis of ADHD and higher rates of substance abuse in adolescent and adults (Biederman et al, 1998; Gittelman et al, 1985; Mannuzza et al, 1998; Milberger et al, 1997; Molina et al, 2009; Wilson and Levin, 2005), treatment itself does not necessarily appear to increase the likelihood of drug use in adolescence and/or adulthood. Among young adults treated as children or currently in treatment, rates of drug, alcohol, or nicotine abuse have been reported to not be significantly different from rates in a sample of healthy untreated controls (Biederman et al, 2008; Mannuzza et al, 2008). In these studies, there was some suggestion that the earlier treatment is initiated the smaller the likelihood of substance abuse in young adulthood. Although this study cannot directly address this issue, as there was only a limited range of ages tested, this is potentially an important avenue for future investigations.

\section{Limitations}

The study is limited by a relatively small sample size, making it difficult to fully evaluate some variables. Trends suggesting that MPH treatment may have influenced some growth measures might have reached significance with larger numbers of animals, for example. Another consideration is that although all animals received doses of MPH designed to maintain serum levels within an effective therapeutic range in children, the doses required to achieve these levels were significantly higher on a $\mathrm{mg} / \mathrm{kg}$ basis than those in children. This may be due to higher rates of drug metabolism in nonhuman primates than in children (Wargin et al, 1983). In addition, because cognitive and/or attentional outcomes were not measured in this study, it cannot be determined if these doses in nonhuman primates are sufficient to alter behavior as intended for treatment of ADHD in children. It is possible that even higher doses might be necessary to produce an effect in nonhuman primates, which would result in significant changes in behavior and potentially DA receptor availability and developmental measures. However, the dose range used in this study produced serum levels in some cases that would 
be considered on the high end of the therapeutic range in humans. The timing of treatment is also an important factor to consider. Although our animals were treated at a common relative age for a child to begin treatment, there is evidence that younger animals are less sensitive to the effects (behavioral) of MPH than older animals, which may be related to the developmental stage of the DA system at time of exposure (Rodriguez et al, 2010). It is certainly possible, therefore, that treating our animals at a different age or for a different duration would have altered our results. A broader range of doses, a wider age range at the initiation of treatment, and variable durations of treatment should be considered in the future. For the self-administration studies, it remains possible that using a different acquisition paradigm may have produced different results.

Finally, when interpreting the results of this study, it is critical to acknowledge that we did not employ a nonhuman primate model of ADHD. The animals treated in this study were 'normal' and thus cannot be easily compared with studies in children or adults with ADHD. This fact may explain the discrepancy between our results and recent results in a study of ADHD adults in which 1 year of treatment resulted in significantly decreased D2/D3 receptor availability as measured by PET (Volkow et al, 2012). An improved understanding of the underlying dopaminergic pathophysiology of ADHD and the development of a reliable model of ADHD in nonhuman primates would be invaluable in future studies of long-term prescription stimulant treatments.

\section{CONCLUSION}

The current findings show that long-term administration of MPH to juvenile nonhuman primates produced no significant alteration in the regulation of the DA systems as measured with PET, or significantly altered growth. These data support the hypothesis that MPH administered in formulations used therapeutically in children does not have obvious long-term effects. In addition, there was no evidence for an increased vulnerability to the reinforcing effects of cocaine in adolescence as a result of MPH treatment. The absence of any significant long-term developmental, neurobiological, or behavioral consequences provides further support that the use of these medications to treat ADHD will not negatively impact children either during or after treatment.

\section{ACKNOWLEDGEMENTS}

We are grateful to Maria Blevins, Jessica Christenson, Christopher Corcoran, and Keith Groach for assistance in data collection and study conduct. We also thank Pradeep Garg, Sudha Garg, Huw Davies, Daniel Morton, Kim Black, and Holly Smith for their efforts collecting PET data, and Tonya Calhoun for her help with the cocaine self-administration studies. We declare that this work was funded by grants from NIDA, DA 20648 (LJP) and DA 06634 (LJP, MAN), NIAAA, AA 17056 (AJB), and T32-AA00756. We wish to acknowledge the generous gift of UCB (Smyrna, GA) for study medication.

\section{DISCLOSURE}

The authors have no other financial interests to disclose, except for JMS who in the past has received the following: prior research support: Alza/McNeil/Janssen, Medeva/UCB, Richwood/Shire, CIBA/Novartis, Noven, Cephalon, Celltech, Gliatech, Watson, Lilly; prior consulting: Alza/McNeil/Janssen, Medeva/UCB, Richwood/Shire, CIBA/Novartis, Noven, Cephalon, Celltech, Gliatech, Watson, Lilly; prior advisory board: Alza/McNeil/Janssen, Medeva/UCB, Richwood/Shire, CIBA/Novartis, Noven, Cephalon, Gliatech; and prior speaker's bureau: McNeil, UCB, Shire, Janssen, Novartis, Cephalon.

\section{REFERENCES}

Andersen SL, Arvanitogiannis A, Pliakas AM, LeBlanc C, Carlezon Jr WA (2002). Altered responsiveness to cocaine in rats exposed to methylphenidate during development. Nat Neurosci 5: 13-14.

Barkley RA, Fischer M, Smallish L, Fletcher K (2003). Does the treatment of attention-deficit/hyperactivity disorder with stimulants contribute to drug use/abuse? A 13-year prospective study. Pediatrics 111: 97-109.

Bennett AJ, Pierre PJ (2010). Nonhuman primate research contributions to understanding genetic and environmental influences on phenotypic outcomes across development. In: Hood K, Halpern CT, Greenberg G, Lerner R (eds). The Handbook of Developmental Science, Behavior, and Genetics. John Wiley \& Sons: Hoboken, NJ, pp 353-399.

Biederman J, Monuteaux MC, Spencer T, Wilens TE, Macpherson HA, Faraone SV (2008). Stimulant therapy and risk for subsequent substance use disorders in male adults with ADHD: a naturalistic controlled 10-year follow-up study. Am J Psychiatry 165: 597-603.

Biederman J, Spencer TJ, Monuteaux MC, Faraone SV (2010). A naturalistic 10-year prospective study of height and weight in children with attention-deficit hyperactivity disorder grown up: sex and treatment effects. J Pediatr 157: 635-640, 640 e631.

Biederman J, Wilens T, Mick E, Spencer T, Faraone SV (1999). Pharmacotherapy of attention-deficit/hyperactivity disorder reduces risk for substance use disorder. Pediatrics 104: e20.

Biederman J, Wilens TE, Mick E, Faraone SV, Spencer T (1998). Does attention-deficit hyperactivity disorder impact the developmental course of drug and alcohol abuse and dependence? Biol Psychiatry 44: 269-273.

Brandon CL, Marinelli M, Baker LK, White FJ (2001). Enhanced reactivity and vulnerability to cocaine following methylphenidate treatment in adolescent rats. Neuropsychopharmacology 25: 651-661.

Carlezon Jr WA, Mague SD, Andersen SL (2003). Enduring behavioral effects of early exposure to methylphenidate in rats. Biol Psychiatry 54: 1330-1337.

Crawford CA, Baella SA, Farley CM, Herbert MS, Horn LR, Campbell RH et al (2011). Early methylphenidate exposure enhances cocaine self-administration but not cocaine-induced conditioned place preference in young adult rats. Psychopharmacology (Berl) 213: 43-52.

Czoty PW, Gage HD, Nader SH, Reboussin BA, Bounds M, Nader MA (2007). PET imaging of dopamine D2 receptor and transporter availability during acquisition of cocaine self-administration in rhesus monkeys. J Addict Med 1: 33-39.

Czoty PW, McCabe C, Nader MA (2005). Assessment of the relative reinforcing strength of cocaine in socially housed monkeys using a choice procedure. J Pharmacol Exp Ther 312: 96-102.

Dalley JW, Fryer TD, Brichard L, Robinson ES, Theobald DE, Laane $\mathrm{K}$ et al (2007). Nucleus accumbens D2/3 receptors predict trait impulsivity and cocaine reinforcement. Science 315: 1267-1270. 
Gal J, Ames MM (1977). Gas-chromatographic resolution of the enantiomers of 3-(3,4-dihydroxyphenyl)alanine and its alpha-methyl analog. Anal Biochem 83: 266-273.

Gittelman R, Mannuzza S, Shenker R, Bonagura N (1985). Hyperactive boys almost grown up. I. Psychiatric status. Arch Gen Psychiatry 42: 937-947.

Harvey RC, Sen S, Deaciuc A, Dwoskin LP, Kantak KM (2011). Methylphenidate treatment in adolescent rats with an attention deficit/hyperactivity disorder phenotype: cocaine addiction vulnerability and dopamine transporter function. Neuropsychopharmacology 36: 837-847.

Hebert MA, Larson GA, Zahniser NR, Gerhardt GA (1999). Agerelated reductions in [3H]WIN 35,428 binding to the dopamine transporter in nigrostriatal and mesolimbic brain regions of the fischer 344 rat. J Pharmacol Exp Ther 288: 1334-1339.

Izenwasser S, Coy AE, Ladenheim B, Loeloff RJ, Cadet JL, French D (1999). Chronic methylphenidate alters locomotor activity and dopamine transporters differently from cocaine. Eur J Pharmacol 373: 187-193.

Knickmeyer RC, Styner M, Short SJ, Lubach GR, Kang C, Hamer R et al (2010). Maturational trajectories of cortical brain development through the pubertal transition: unique species and sex differences in the monkey revealed through structural magnetic resonance imaging. Cereb Cortex 20: 1053-1063.

Lambert NM, Hartsough CS (1998). Prospective study of tobacco smoking and substance dependencies among samples of ADHD and non-ADHD participants. J Learn Disabil 31: 533-544.

Logan J, Fowler JS, Volkow ND, Wang GJ, Ding YS, Alexoff DL (1996). Distribution volume ratios without blood sampling from graphical analysis of PET data. J Cereb Blood Flow Metab 16: 834-840

Ma SY, Ciliax BJ, Stebbins G, Jaffar S, Joyce JN, Cochran EJ et al (1999). Dopamine transporter-immunoreactive neurons decrease with age in the human substantia nigra. J Comp Neurol 409: 25-37.

Mannuzza S, Klein RG, Bessler A, Malloy P, LaPadula M (1998). Adult psychiatric status of hyperactive boys grown up. Am J Psychiatry 155: 493-498.

Mannuzza S, Klein RG, Truong NL, Moulton III JL, Roizen ER, Howell $\mathrm{KH}$ et al (2008). Age of methylphenidate treatment initiation in children with ADHD and later substance abuse: prospective follow-up into adulthood. Am J Psychiatry 165: 604-609.

Meng SZ, Ozawa Y, Itoh M, Takashima S (1999). Developmental and age-related changes of dopamine transporter, and dopamine D1 and D2 receptors in human basal ganglia. Brain Res 843: 136-144.

Milberger S, Biederman J, Faraone SV, Wilens T, Chu MP (1997). Associations between ADHD and psychoactive substance use disorders. Findings from a longitudinal study of high-risk siblings of ADHD children. Am J Addict 6: 318-329.

Molina BS, Hinshaw SP, Swanson JM, Arnold LE, Vitiello B, Jensen PS et al (2009). The MTA at 8 years: prospective follow-up of children treated for combined-type ADHD in a multisite study. J Am Acad Child Adolesc Psychiatry 48: 484-500.

Moll GH, Hause S, Ruther E, Rothenberger A, Huether G (2001). Early methylphenidate administration to young rats causes a persistent reduction in the density of striatal dopamine transporters. J Child Adolesc Psychopharmacol 11: 15-24.

Nader MA, Morgan D, Gage HD, Nader SH, Calhoun TL, Buchheimer $\mathrm{N}$ et al (2006). PET imaging of dopamine D2 receptors during chronic cocaine self-administration in monkeys. Nat Neurosci 9: 1050-1056.

NRC/NAS (2003). Nutrient Requirements of Nonhuman Primates: Second Revised Edition Sciences NRCoTNAo (ed) Washington, DC.

Patrick KS, Gonzalez MA, Straughn AB, Markowitz JS (2005). New methylphenidate formulations for the treatment of atten- tion-deficit/hyperactivity disorder. Expert Opin Drug Deliv 2: 121-143.

Pelham WE, Gnagy EM, Burrows-Maclean L, Williams A, Fabiano GA, Morrisey SM et al (2001). Once-a-day Concerta methylphenidate versus three-times-daily methylphenidate in laboratory and natural settings. Pediatrics 107: E105.

Rapoport JL, Inoff-Germain G (2002). Responses to methylphenidate in Attention-Deficit/Hyperactivity Disorder and normal children: update 2002. J Atten Disord 6(Suppl 1): S57-S60.

Rodriguez JS, Morris SM, Hotchkiss CE, Doerge DR, Allen RR, Mattison DR et al (2010). The effects of chronic methylphenidate administration on operant test battery performance in juvenile rhesus monkeys. Neurotoxicol Teratol 32: 142-151.

Safer D, Allen R, Barr E (1972). Depression of growth in hyperactive children on stimulant drugs. $N$ Engl J Med 287: 217-220.

Schenk S, Izenwasser S (2002). Pretreatment with methylphenidate sensitizes rats to the reinforcing effects of cocaine. Pharmacol Biochem Behav 72: 651-657.

Schweri MM, Skolnick P, Rafferty MF, Rice KC, Janowsky AJ, Paul SM (1985). [3H]Threo-(+/-)-methylphenidate binding to 3,4dihydroxyphenylethylamine uptake sites in corpus striatum: correlation with the stimulant properties of ritalinic acid esters. J Neurochem 45: 1062-1070.

Seeman P, Bzowej NH, Guan HC, Bergeron C, Becker LE, Reynolds GP et al (1987). Human brain dopamine receptors in children and aging adults. Synapse 1: 399-404.

Segal JL, Cunningham RF, Dayton PG, Israili ZH (1976). (14C)Methylphenidate hydrochloride. Studies on disposition in rat brain. Drug Metab Dispos 4: 140-146.

Self DW (2004). Regulation of drug-taking and -seeking behaviors by neuroadaptations in the mesolimbic dopamine system. Neuropharmacology 47(Suppl 1): 242-255.

Simchon Y, Weizman A, Rehavi M (2010). The effect of chronic methylphenidate administration on presynaptic dopaminergic parameters in a rat model for ADHD. Eur Neuropsychopharmacol 20: 714-720.

Swanson JM, Agler D, Fineberg E, Wigal S, Flynn D, Fineberg K et al (1999). UCI laboratory school protocol for PK-PD studies. In: Greenhill LL, Osman B (eds). Ritalin: Theory and Practice, 2nd edn Mary Ann Liebert Publishers: New Rochelle, NY. pp 405-430.

Swanson JM, Elliott GR, Greenhill LL, Wigal T, Arnold LE, Vitiello $B$ et al (2007). Effects of stimulant medication on growth rates across 3 years in the MTA follow-up. J Am Acad Child Adolesc Psychiatry 46: 1015-1027.

Swanson JM, Volkow ND (2003). Serum and brain concentrations of methylphenidate: implications for use and abuse. Neurosci Biobehav Rev 27: 615-621.

Swanson JM, Volkow ND (2009). Psychopharmacology: concepts and opinions about the use of stimulant medications. $J$ Child Psychol Psychiatry 50: 180-193.

Swanson JM, Wigal SB, Wigal T, Sonuga-Barke E, Greenhill LL, Biederman J et al (2004). A comparison of once-daily extendedrelease methylphenidate formulations in children with attentiondeficit/hyperactivity disorder in the laboratory school (the Comacs Study). Pediatrics 113(3 Pt 1): e206-216.

Tanner JM (1986). Normal growth and techniques of growth assessment. Clin Endocrinol Metabol 15: 411-451.

Teicher MH, Andersen SL, Hostetter Jr JC (1995). Evidence for dopamine receptor pruning between adolescence and adulthood in striatum but not nucleus accumbens. Brain Res Dev Brain Res 89: $167-172$.

Thanos PK, Michaelides M, Benveniste H, Wang GJ, Volkow ND (2007). Effects of chronic oral methylphenidate on cocaine selfadministration and striatal dopamine D2 receptors in rodents. Pharmacol Biochem Behav 87: 426-433.

Visser SN, Lesesne CA, Perou R (2007). National estimates and factors associated with medication treatment for childhood 
attention-deficit/hyperactivity disorder. Pediatrics 119(Suppl 1): S99-S106.

Volkow ND, Ding YS, Fowler JS, Wang GJ, Logan J, Gatley SJ et al (1996). Dopamine transporters decrease with age. J Nucl Med 37: 554-559.

Volkow ND, Fowler JS, Wang GJ (1999). Imaging studies on the role of dopamine in cocaine reinforcement and addiction in humans. J Psychopharmacol 13: 337-345.

Volkow ND, Insel TR (2003). What are the long-term effects of methylphenidate treatment? Biol Psychiatry 54: 1307-1309.

Volkow ND, Wang GJ, Fowler JS, Gatley SJ, Logan J, Ding YS et al (1998). Dopamine transporter occupancies in the human brain induced by therapeutic doses of oral methylphenidate. Am J Psychiatry 155: 1325-1331.

Volkow ND, Wang GJ, Tomasi D, Kollins SH, Wigal TL, Newcorn $\mathrm{JH}$ et al (2012). Methylphenidate-elicited dopamine increases in ventral striatum are associated with long-term symptom improvement in adults with attention deficit hyperactivity disorder. J Neurosci Off J Soc Neurosci 32: 841-849.

Wargin W, Patrick K, Kilts C, Gualtieri CT, Ellington K, Mueller RA et al (1983). Pharmacokinetics of methylphenidate in man, rat and monkey. J Pharmacol Exp Ther 226: 382-386.

Weerts EM, Fantegrossi WE, Goodwin AK (2007). The value of nonhuman primates in drug abuse research. Exp Clin Psychopharmacol 15: 309-327.

Wilson JJ, Levin FR (2005). Attention-deficit/hyperactivity disorder and early-onset substance use disorders. J Child Adolesc Psychopharmacol 15: 751-763.

Wolf ME, Sun X, Mangiavacchi S, Chao SZ (2004). Psychomotor stimulants and neuronal plasticity. Neuropharmacology 47 (Suppl 1): 61-79.

Zhang H, Du M, Zhuang S (2010). Impact of long-term treatment of methylphenidate on height and weight of school age children with ADHD. Neuropediatrics 41: 55-59. 